\title{
Correction to: Transcatheter Mitral Valve Implantation Systematic Review: Focuson Transseptal Approach and Mitral Annulus Calcification
}

\author{
W. Ben-Ali ${ }^{1,2,3} \cdot$ R. Ibrahim ${ }^{2} \cdot$ J. Rodès-Cabeau ${ }^{4} \cdot$ R. S. von Bardeleben ${ }^{5} \cdot$ D. Mylotte $^{6} \cdot$ J. Granada $^{7} \cdot$ T. Modine $^{1,3}$ \\ Published online: 3 April 2021 \\ (C) Springer Science+Business Media, LLC, part of Springer Nature 2021
}

\section{Correction to: Current Cardiology Reports (2021) 23:37 https://doi.org/10.1007/s11886-021-01466-7}

In the original publication of this article, affiliations 1 and 3 contain some typos and Dr. Modine was not affiliated to affiliation 3. The original article has been corrected.

Publisher's Note Springer Nature remains neutral with regard to jurisdictional claims in published maps and institutional affiliations.

The online version of the original article can be found at https://doi.org/ 10.1007/s11886-021-01466-7

T. Modine

thomasmodine@gmail.com

W. Ben-Ali

dr.walidbenali@gmail.com

R. Ibrahim

hemodynamie@gmail.com

J. Rodès-Cabeau

Josep.Rodes@criucpq.ulaval.ca

R. S. von Bardeleben

stephan.von_bardeleben@unimedizin-mainz.de

D. Mylotte

darrenmylotte@gmail.com

J. Granada

jgranada@crf.org
1 Service Médico-Chirurgical: Valvulopathies- Chirurgie CardiaqueCardiologie Interventionelle Structurelle, Hôpital Cardiologique de Haut Lévèque, CHU-Bordeaux, Bordeaux, France

2 Structural Valve Program, Montreal Heart Institute, Montréal, Canada

3 Service de Chirurgie, Cardio-vasculaire Hôpital haut Leveque, CHU-Bordeaux, Avenue de Magellan 33604, Pessac Cedex, France

4 Quebec Heart and Lung Institute, Laval University, Quebec City, Canada

5 Heart Valve Center Mainz, Universitätsmedizin, Mainz, Germany

6 Department of Cardiology, University Hospital of Galway, Galway, Ireland

Cardiovascular Research Foundation, CRF Skirball Center for Innovation, Columbia University Medical Center, New York, USA 